\title{
PERANCANGAN JARINGAN VIRTUAL METAMETAROUTER
}

\author{
Abdul Rozak ${ }^{1}$, Ahmad S. Pardiansyah ${ }^{2}$ \\ Program Studi Teknik Informatika, STMIK Lombok \\ Jln. Basuki Rahmat No.105 Praya Lombok Tengah 83511 \\ ahmad.pardiansyah84@gmail.com
}

\begin{abstract}
SMK BangunBangsa have computer networking hardware to do the lab network, but the device is a computer network that is owned by SMK Bangun Bangsa are very limited one example, the lack of devices MetaRouterboard, while in the lab network SMK Bangu Bangsa want to simulate a LAN and MAN real simulation but limitations of network devices. So some questions arise: Is simulated LAN and MAN networks can be implemented while the lack of hardware support on vocational Build People?

In this study, researchers have conducted the data collection methods and apply methods of analysis, from the results, the researchers have to get a solution to implement the LAN and MAN networks simulating real simulation with "Designing Virtual Networking MetaMetaRouter", using design methods PPDIOO.

Implementation of Virtual MetaMetaRouter at SMK Bangun Bangsa, both LAN and MAN networks simulating real simulation can ultimately be applied and save in the procurement of network hardware.
\end{abstract}

Keywords: Virtual Meta Meta Router, PPDIOO.

\begin{abstract}
Abstrak
SMK Bangun Bangsa memiliki perangkat keras jaringan komputer untuk melakukan jaringan laboratorium, namun perangkat yang merupakan jaringan komputer yang dimiliki oleh SMK Bangun Bangsa ini sangat terbatas satu contohnya, minimnya perangkat MetaRouterboard, sedangkan di laboratorium jaringan SMK Bangun Bangsa ingin mensimulasikan sebuah simulasi nyata LAN dan MAN tapi keterbatasan perangkat jaringan. Maka muncul beberapa pertanyaan: Apakah jaringan LAN dan MAN yang disimulasikan bisa diimplementasikan sedangkan kurangnya dukungan hardware pada SMK bangun bangsa?

Dalam penelitian ini, peneliti telah melakukan metode pengumpulan data dan menerapkan metode analisis, dari hasil, para peneliti harus mendapatkan solusi untuk mengimplementasikan jaringan LAN dan MAN simulasi simulasi nyata dengan "Designing Virtual Networking MetaMetaRouter", dengan menggunakan metode desain PPDIOO. .

Implementasi Virtual MetaMetaRouter di SMK BangunBangsa, baik jaringan LAN maupun MAN simulasi simultan sebenarnya dapat diaplikasikan dan disimpan dalam pengadaan perangkat keras jaringan.
\end{abstract}

Kata kunci : Virutal MetaMetaRouter, PPDIOO. 


\section{Pendahuluan}

Pada era tekonologi informasi seperti saat ini, perkembangan teknologi gadget maupun laptop amat pesat. Hampir tiap manusia di muka bumi ini memiliki "minimal" satu perangkat gadget maupun perangkat teknologi informasi lainnya, dan tidak dapat dipungkiri bahwa perangkat-perangkat tersebut selalu membutuhkan akses ke internet. (Rendra Towidjojo, 2015).

Peralatan dan perangkat yang mendukung system jaringan ke akses internet seperti MetaRouterboard, Switch, Hub, Bridge, Repeater, Modem. Berbagai teknologi dan system baru baik dari perangkat keras jaringan maupun perangkat lunak jaringan bermunculan. Namun harga dari sebuah perangkat keras jaringan semakin hari semakin mahal, sehingga user dalam bidang IT sangat sulit melakukan riil simulation dalam dunia jaringan. (S'To, 2016).

Salah satu studi kasus SMK Bangun Bangsa yang memiliki bidang konsentrasi teknologi jaringan computer atau sering disebut konsentrasi TKJ, memiliki fasilitas perangkat keras jaringan yang kurang mendukung hanya memiliki satu MetaRouterboard sebagai media pembelajaran dan mengandalkan perangkat lunak packet tracer untuk melakukan simulasi, dalam dunia jaringan membutuhkan riil simulation dan membutuhkan banyak MetaRouter-MetaRouter yang digunakan terutama simulasi jaringan LAN (Local Area Network) dan MAN (Metropolitan Area Network).

Dengan kurangnya fasilitas perangkat keras jaringan dan harganya semakin tinggi maka peneliti memberikan sebuah solusi dalam melakukan riil simulation yaitu " PERANCANGAN JARINGAN VIRTUAL METAMETAROUTER (Studi Kasus SMK Bangun Bangsa)”.

Ada beberapa permasalahan yang ditemukan pada SMK Bangun Bangsa adalah Apakah dengan penerapan perancangan jaringan virtual MetaMetaRouter secara riil simulation dengan kurangnya fasilitas jaringan pada SMK Bangun Bangsa dapat menghemat biaya jaringan computer, Apakah fitur MetaMetaRouter dapat diterapkan 100\% terkoneksi pada MetaRouterboard untuk melakukan perancangan jaringan virtual MetaMetaRouter riil simulation pada SMK Bangun Bangsa, apakah dengan memanfaatkan satu MetaRouterboard untuk melakukan riil simulation dengan penerapan MetaMetaRouter untuk jaringan LAN dan MAN pada SMK Bangun Bangsa dapat terpenuhi.
Tujuan dari perancangan jaringan virtual MetaMetaRouter pada SMK Bangun Bangsa adalah :

a. Segi ekonomi, penghematan pembelian perangkat jaringan komputer pada SMK Bangun Bangsa.

b. Segi koneksi jaringan komputer, perancangan jaringan MAN cukup menggunakan 1 (Satu) ISP Internet Service Provider pada SMK Bangun Bangsa.

c. MetaMetaRouter dapat diimplementasikan pada SMK Bangun Bangsa setelah hasil uji terkoneksi 100 $\%$.

\section{Tinjuan Pustaka}

Menurut Dwi Hermanto (2015) dalam naskah publikasinya "Analisis Dan Implementasi Fitur MetaMetaRouter Mikrotik Untuk Loadbalance Dan Qos Menggunakan Mikrotik RB751U-2HND Pada Jaringan Global Media Solusindo", menyatakan bahwa :

a. MetaMetaRouter merupakan fitur Mikrotik yang memungkinkan untuk menjalankan operating system baru secara virtual. Hampir sama seperti aplikasi VMware atau Virtual PC pada Windows. MetaMetaRouter bisa digunakan untuk menjalankan operating system di dalam OS Mikrotik yang sedang berjalan.

b. Mikrotik MetaRouter OS, merupakan OS berbasis Linux yang di desain khusus sebagai MetaRouter. Mikrotik memiliki berbagai macam fitur perutean seperti firewall, pengaturan trafik atau Qos, akses point nirkabel, hotspot dan virtualisasi.

Menurut S'to (2016) dalam bukunya "Mikrotik MetaMetaRouter 100\% Illusion" MetaRouterOS sebagai system operasi dari MetaRouter Mikrotik, sudah memiliki dukungan untuk menerapkan virtualisasi, baik itu penerapan virtualisasi MetaRouter maupun virtualisasi topologi jaringan. MetaRouterOS mendukung tiga kategori teknik virtualisasi berbeda yang terdiri dari :

a. MetaMetaRouter, dengan MetaMetaRouter sebuah MetaRouterOS akan mampu menjalankan beberapa MetaRouterOS lainnya dalam bentuk virtual. Selain MetaRouterOS, MetaMetaRouter dapat menjalankan system operasi linux, namun hanya untuk system linux openWRT.

b. Xen, dengan teknik ini, sebuah MetaRouterOS dapat menjalankan beberapa MetaRouterOS lainnya dalam bentuk virtual. Selain itu, Xen juga akan mampu menjalankan beberapa system operasi lain yang didukung oleh arsitektur hardware MetaRouter yang digunakan. Xen 
adalah virtualisasi yang dapat dijalankan oleh MetaRouterOS untuk tipe MetaRouter dengan platform hardware $x 86$.

KVM (Kernal-based Virtual Machine), dengan metode ini, sebuah MetaRouterOS dapat menjalankan beberapa sistem operasi lain. Namun, KVM hanya bisa digunakan untuk MetaRouter yang menggunakan platform mesin x86, dan mesin tersebut harus menggunakan CPU (Processor) yang sudah mendukung virtualisasi.

\section{Metodologi Penelitian}

Metode penelitian yang digunakan penulis adalah sebagai berikut :

1. Metode Pengumpulan Data

2. Metode Analisis Jaringan

3. Metode Perancangan Jaringan

4. Metode Testing

\section{Hasil dan Pembahasan}

Adapun bentuk jaringan praktikum riil simulation yang direncanakan untuk digunakan pada SMK Bangun Bangsa yaitu membutuhkan beberapa MetaRouter untuk melakukan simulasi jaringan riil simulation.

Dengan ketergantungan penggunaan beberapa MetaRouter, SMK Bangun Bangsa harus mengadakan perangkat jaringan, akan tetapi keterbatasan untuk mengadakan perangkat jaringan sangat minim.

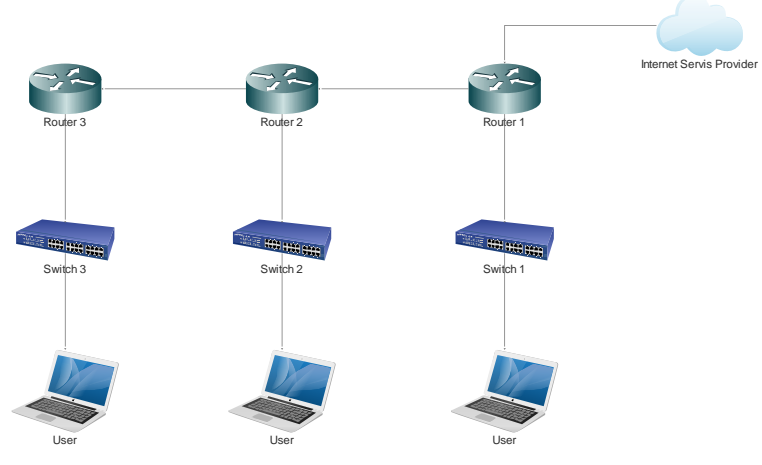

Gambar 1 Topologi Jaringan SMK Bangun Bangsa

Dalam menganalisa masalah yang terjadi pada SMK Bangun Bangsa peneliti menggunakan Metode Analisis Akar Masalah dan Solusi (MAAMS) dengan pendekatan 5 Whys (Where, When, Why, Who, and What) untuk mendapatkan bukti yang akurat dari permasalahan yang terjadi.

Tabel 1 Identitas Peneliti dan Guru Konfigurasi LAN

\begin{tabular}{|c|c|}
\hline Peneliti & Guru Konfigurasi LAN \\
\hline Abdul Rozak, & Suhartandi, S.Pd \\
Ahmad Susan \\
Pardiansyah
\end{tabular}

Tabel 2 Wawancara Peneliti dan Guru Konfigurasi LAN

\begin{tabular}{|c|c|}
\hline $\begin{array}{l}\text { Apa jenis } \\
\text { perangkat } \\
\text { hardware jaringan } \\
\text { yang terdapat } \\
\text { pada Lab SMK } \\
\text { Bangun Bangsa? }\end{array}$ & $\begin{array}{lr}\text { Modem, } & \text { Switch, } \\
\text { MetaRouterboard, } & \\
\text { Komputer, LCD, Tank } \\
\text { Krimping, LAN } & \text { Tester, } \\
\text { Kabel UTP dan Konektor } \\
\text { RJ 45 }\end{array}$ \\
\hline $\begin{array}{l}\text { Apa permasalahan } \\
\text { yang paling } \\
\text { mendasar ketika } \\
\text { melakukan } \\
\text { praktikum TKJ? }\end{array}$ & $\begin{array}{l}\text { Kami ingin melakukan } \\
\text { Praktikum jaringan LAN } \\
\text { dan MANriil simulation. } \\
\text { Namun keterbatasan } \\
\text { perangkat hardware }\end{array}$ \\
\hline $\begin{array}{lr}\text { Apa } & \text { perangkat } \\
\text { hardware } & \text { yang } \\
\text { paling } & \text { mendasar } \\
\text { yang dibutuhkan } \\
\text { SMK } \\
\text { Bangsa? }\end{array}$ & $\begin{array}{lr}\text { Karena kami } & \text { ingin } \\
\text { melakukan } & \text { praktikum } \\
\text { jaringan LAN dan MAN riil } & \text { kami } \\
\text { simulation, } & \text { kambutuhkn } \\
\text { membeberapa } \\
\text { MetaRouter. }\end{array}$ \\
\hline $\begin{array}{l}\text { Berapakah } \\
\text { perangkat } \\
\text { MetaRouter yang } \\
\text { dibutuhkan SMK } \\
\text { Bangun Bangsa } \\
\text { untuk melakukan } \\
\text { praktikum } \\
\text { jaringan LAN dan } \\
\text { MAN? }\end{array}$ & $\begin{array}{lr}\text { Minimal } & \text { kami } \\
\text { membutuhkan } \quad 3 & \text { buah } \\
\text { MetaRouterboard } & \text { dan } \\
\text { maksimal } 5 & \text { buah } \\
\text { MetaRouterboard. } & \end{array}$ \\
\hline $\begin{array}{l}\text { Kenapa SMK } \\
\text { Bangun Bangsa } \\
\text { tidak mengadakan } \\
\text { perangkat } \\
\text { MetaRouter, } \\
\text { sehingga bisa } \\
\text { melakukan } \\
\text { praktikum? }\end{array}$ & $\begin{array}{l}\text { Itulah sebabnya kami tidak } \\
\text { bisa melakukan praktikum } \\
\text { riil simulation, kekurangan } \\
\text { dari segi materi untuk } \\
\text { mengadakan perangkat } \\
\text { hardware yang seperti itu. }\end{array}$ \\
\hline $\begin{array}{l}\text { Bagaimana dengan } \\
\text { aplikasi Packet } \\
\text { Tracer dan GNS3? }\end{array}$ & $\begin{array}{l}\text { Jika kami menggunakan } \\
\text { aplikasi Packet Tracer dan } \\
\text { GNS3 istilahnya kami } \\
\text { sedang merancang } \\
\text { jaringan secara khayalan, } \\
\text { sedangkan secara nyata itu } \\
\text { jauh lebih beda hasilnya. }\end{array}$ \\
\hline \multirow[t]{2}{*}{$\begin{array}{l}\text { Apakah tipe } \\
\text { MetaRouterboard } \\
\text { yang dimiliki SMK } \\
\text { Bangun Bangsa? } \\
\end{array}$} & $\begin{array}{l}\text { Kami memiliki } \\
\text { MetaRouterboardRB951Ui- } \\
\text { 2nD }\end{array}$ \\
\hline & $\begin{array}{lr}\text { Adakah solusi } & \text { yang bisa } \\
\text { diterapkan } & \text { untuk } \\
\text { melakukan } & \text { praktikum } \\
\end{array}$ \\
\hline
\end{tabular}




\begin{tabular}{|l|l|}
\hline jaringan riil simulation \\
LAN dan MAN dengan \\
keterbatasan perangkat \\
hardware jaringan kami \\
pada SMK Bangun Bangsa?
\end{tabular}

Berikut Spesifikasi Hardware dan software yang digunakan dalam penelitian:

Tabel 3 Spesifikasi Hardware

\begin{tabular}{|l|l|}
\hline Product Code & CRS125-24G-1S-IN \\
\hline Architecture & MIPS-BE \\
\hline CPU & AR9344 600MHz \\
\hline Current Monitor & No \\
\hline Main Storage/NAND & $128 \mathrm{MB}$ \\
\hline RAM & $128 \mathrm{MB}$ \\
\hline SFP Ports & 1 \\
\hline LAN Ports & 24 \\
\hline Gigabit & Yes \\
\hline Switch Chip & 3 \\
\hline MiniPCI & 0 \\
\hline Integrated Wireless & No \\
\hline MiniPCIe & 0 \\
\hline SIM Card Slots & No \\
\hline Power on USB & Yes \\
\hline Memory Cards & No \\
\hline Power Jack & No \\
\hline 802.3af Support & No \\
\hline POE Input & Yes \\
\hline POE Output & No \\
\hline Serial Port & Yes \\
\hline Voltage Monitor & Yes \\
\hline Temprature Sensor & Yes \\
\hline Dimentions & $285 \times 145 \times 45 m m$ \\
\hline Operating System & MetaRouterOS \\
\hline Temprature Range & $-30 . .+70 C$ \\
\hline $\begin{array}{l}\text { MetaRouterOS } \\
\text { License }\end{array}$ & Level5 \\
\hline
\end{tabular}

Tabel 4 Spesifikasi MetaRouterOS

\begin{tabular}{|l|l|}
\hline Uptime & $46 \mathrm{~m} 14 \mathrm{~s}$ \\
\hline Version & 6.36 .4 (bugfix) \\
\hline Buid-time & $\begin{array}{l}\text { Oct/05/2016 } \\
11: 24: 22\end{array}$ \\
\hline Free-memory & $94.0 \mathrm{MiB}$ \\
\hline Total-memory & $128.0 \mathrm{MiB}$ \\
\hline CPU & MIPS 74Kc V4.12 \\
\hline CPU-Count & 1 \\
\hline CPU-Frequency & $600 \mathrm{MHz}$ \\
\hline CPU-load & $7 \%$ \\
\hline Free-hdd-space & $105.9 \mathrm{MiB}$ \\
\hline Total-hdd-space & $128.0 \mathrm{MiB}$ \\
\hline $\begin{array}{l}\text { Write-sect-since- } \\
\text { reboot }\end{array}$ & 804 \\
\hline Write-sect-total & 13407 \\
\hline Bad-blocks & $0.2 \%$ \\
\hline Architecture-name & Mipsbe \\
\hline
\end{tabular}

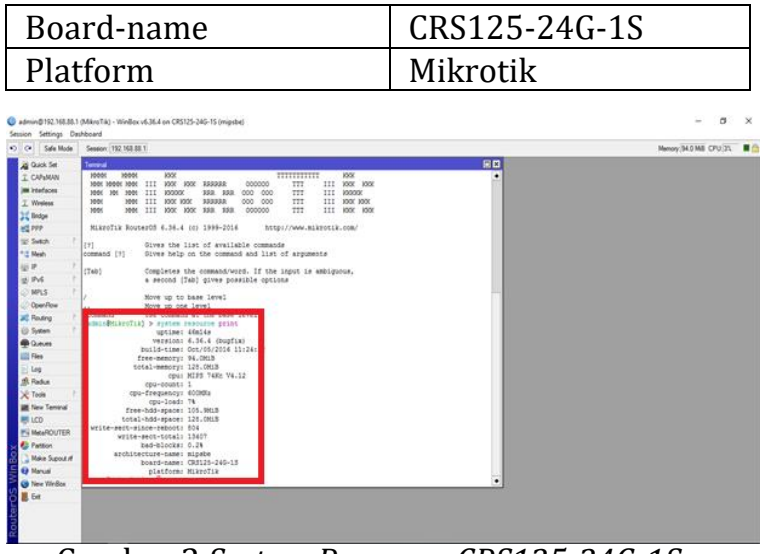

Gambar 2 System Resource CRS125-24G-1S

Interface MetaMetaRouter diperlukan untuk menghubungkan MetaRouter tersebut dengan jaringan, baik itu dengan itu perangkat switch, komputer maupun dengan sesame MetaRouter. Begitu pula dengan MetaMetaRouter yang membutuhkan interface sehingga dapat terhubung ke jaringan.

Interface pada MetaMetaRouter dapat digunakan untuk membangun hubungan dengan network yang sebenarnya (terhubung keperangkat lain di luar dan MetaRouter Cloud). Selain itu, interface pada MetaMetaRouter juga dapat digunakan untuk membangun hubungan dengan sesama MetaMetaRouter lainnya.

Dalam gambar ilustrasi di bawah ini yang memperlihatkan sebuah MetaRouterboard yang sudah memiliki 2 (dua) unit MetaMetaRouter. MetaMetaRouter yang pertama, sebut saja dia sebagai R1 sedangkan MetaMetaRouter yang kedua sebut saja dia sebagai R2

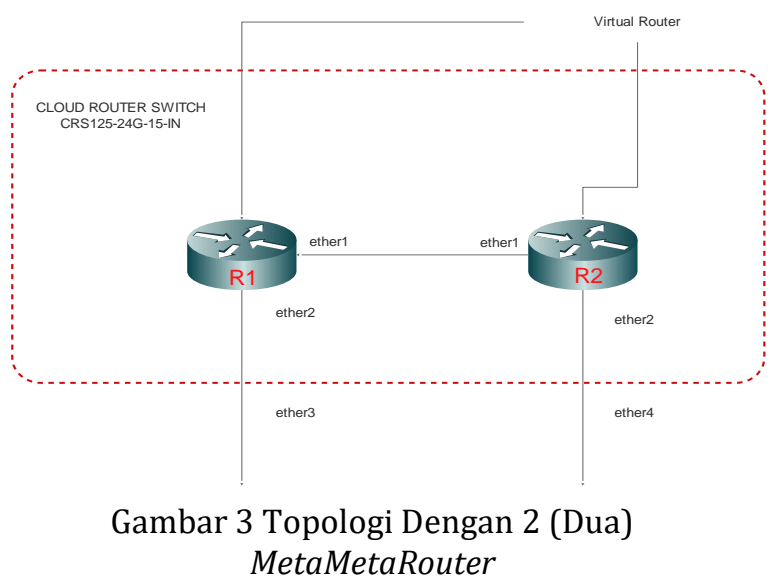

Dari gambar 3 dapat dilihat bahwa MetaRouter 1 (R1) memiliki 2 (dua) Interface yakni interface Ether 1 dan Ether 2. Interface ether1 milik MetaRouter R1 terhubung ke interface ether1 milik MetaRouter R2, dan 
ternyata MetaRouter R2 ini juga merupakan MetaMetaRouter. Sedangkan interface ether2 dari MetaRouter R1 terhubung ke network luar (outside).

MetaRouter R1 merupakan MetaMetaRouter nantinya dapat terhubung dengan perangkat lain yang berada di luar MetaRouter Cloud. Perhatikanlah gambar $4.14 \quad$ yang memperlihatkan bahwa MetaRouter R1 sudah bisa terhubung dengan switch maupun beberapa komputer yang berada di dunia luar.

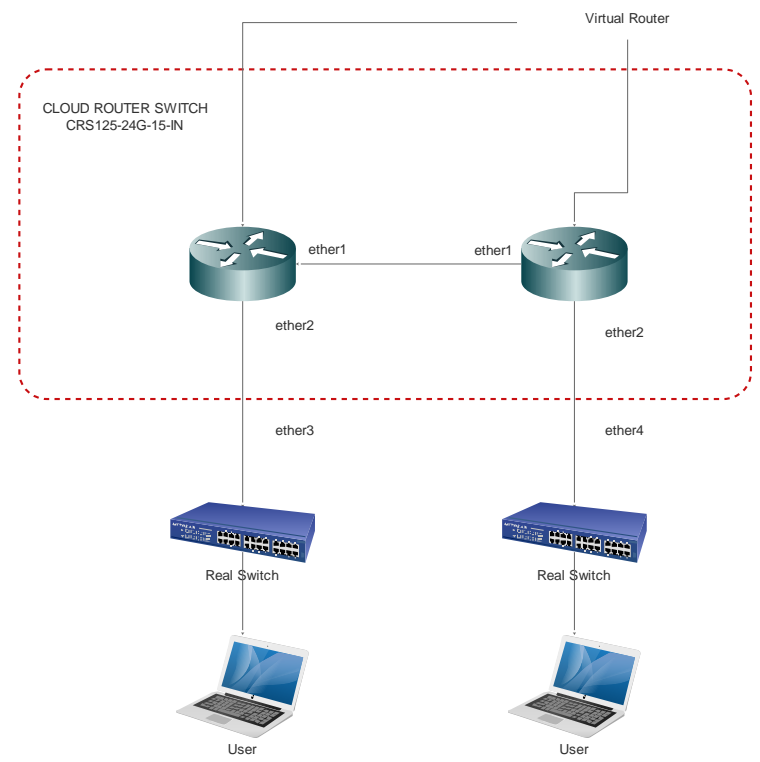

Gambar 4 Topologi Terhubung Dengan Device Luar

Untuk melihat bagaimana melakukan konfigurasi static interface bagi MetaMetaRouter, maka topologi yang digunakan sebagai acuan adalah :

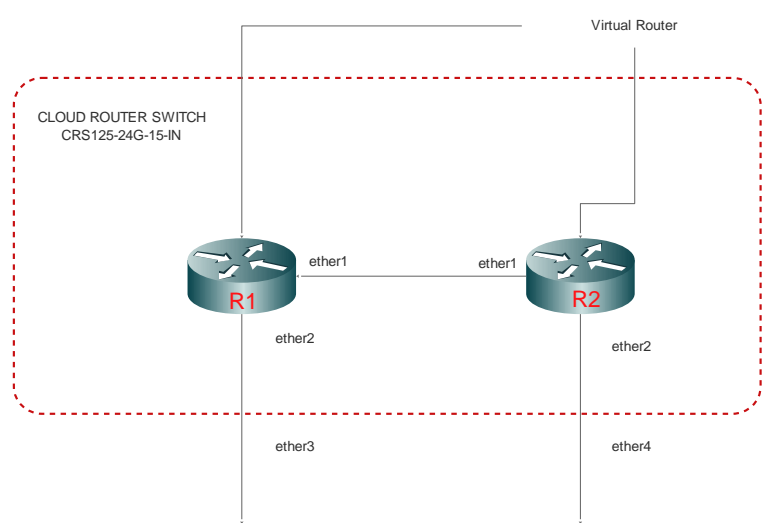

Gambar 5 Topologi Static Interface

Dari gambar 5 terlihat bahwa MetaRouter Cloud memiliki 2 (dua) unit MetaRouter, masingmasing MetaRouter R1 dan R2. Kedua MetaRouter tersebut terhubung satu sama lain, melalui interface ether1 dari masing-masing MetaRouter. Kedua MetaRouter juga terhubung keluar melalui interface ether2 dari masingmasing MetaRouter. Interface ether2 dari MetaRouter R1 terhubung keluar melalui interface ether3 dari MetaRouter Cloud, sedangkan interface ether2 dari MetaRouter R2 terhubung keluar melalui interface ether4 dari MetaRouter Cloud.

\section{Interface virtual-ethernet add name=ether1@R1 \disabled=no}

Gambar 6 Perintah membuat interface virtual ethernet

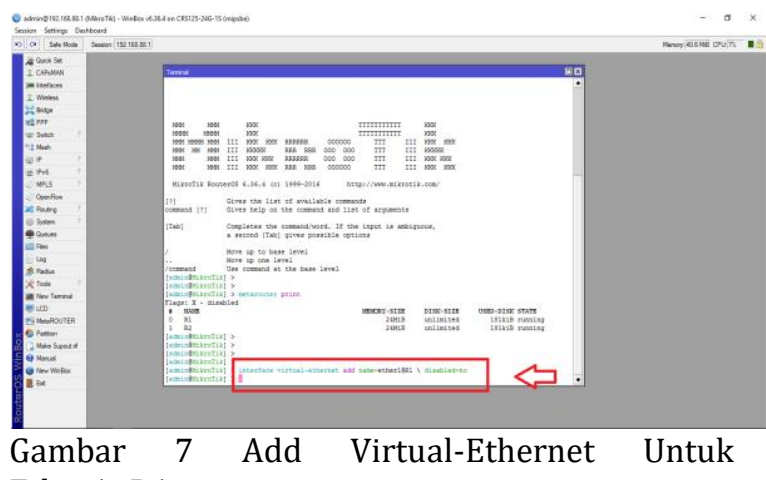

Ether1=R1

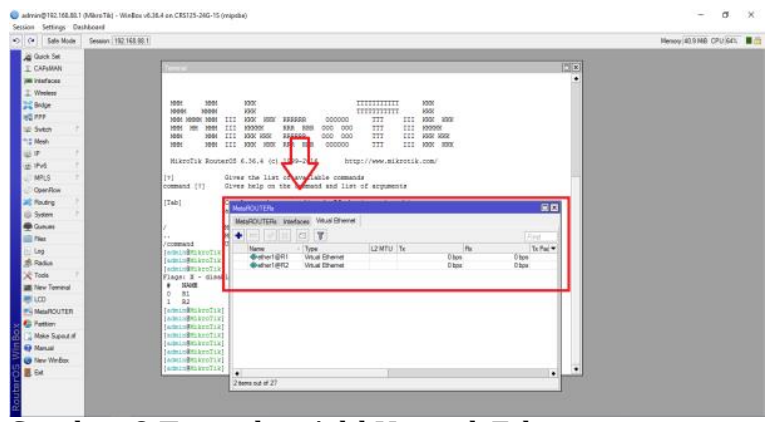

Gambar 8 Tampilan Add Virtual-Ethernet

Langkah selanjutnya adalah memberikan interface ether1@R1 kepada Router R1 dan memberikan interface ether1@R2 kepada Router R2. Perhatikanlah bahwa konfigurasi ini adalah konfigurasi static interface. Perintah yang diketik adalah:

\begin{tabular}{|c|c|}
\hline $\begin{array}{l}\text { Metarouter interface add } \\
\text { machine=R1 } \\
\text { interface=ether1@R1 type=static } \\
\text { Metarouter interface add virtual- } \\
\text { machine=R2 \type=static static- } \\
\text { interface=ether1@R2 }\end{array}$ & $\begin{array}{r}\text { virtual- } \\
\text { static- }\end{array}$ \\
\hline $\begin{array}{l}\text { Gambar } 9 \text { perintah konfigurasi } \\
\text { erface }\end{array}$ & static \\
\hline
\end{tabular}


Dari hasil implementasi jaringan Virtual MetaRouter didapatkan perbedaan hasil penggunaan Router Cloud Switch CSR125-24G1S-IN dengan penerapan MetaRouter adalah sebagai berikut:

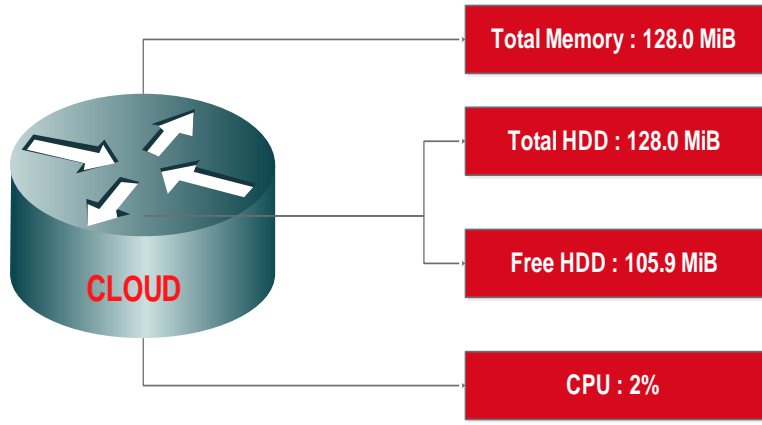

Gambar 10 Spesifikasi Sebelum Penerapan MetaRouter

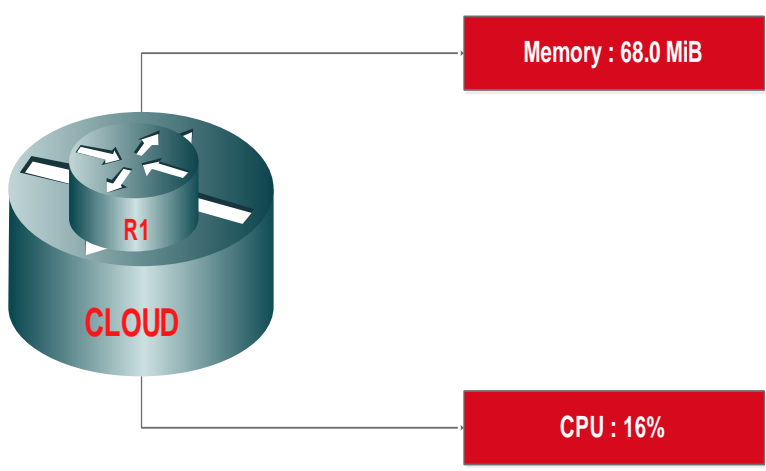

Gambar 11 Setelah Penerapan 1 (Satu) MetaRouter

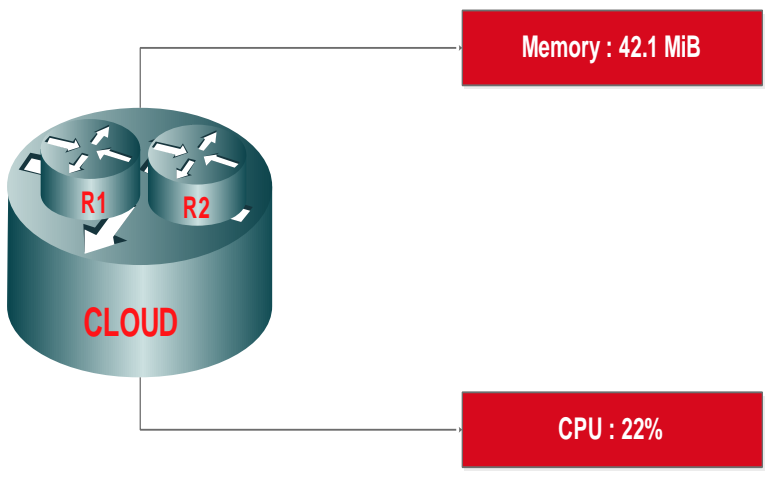

Gambar 11 Setelah Penerapan 2 (Dua) MetaRouter

\section{Kesimpulan Dan Saran}

Kesimpulan dari penelitian ini adalah:

1. Hasil penelitian pada SMK Bangun Bangsa sebelum penerapan jaringan virtual metarouter membutuhkan biaya mahal untuk pembelian router dari segi estimasi ekonomi, setelah peneliti mengimplementasikan jaringan virtual metarouter pada SMK Bangun Bangsa estimasi ekonomi lebih hemat Rp.
2.330.000 dibandingkan sebelum menerapkan virtual Metarouter sebesar Rp.5.930.000

2. Hasil kinerja penerapan dan ujicoba virtual Metarouter pada SMK Bangun Bangsa, terkoneksi $100 \%$ dengan menggunakan routerboard CSR12524G-1S-1N dengan implementasi 2 (Dua) Metarouter pada satu perangkat, berdasarkan hasil implementasi.

Saran dari penelitian ini adalah:

1. Dalam pengujian virtual MetaRouter peneliti menggunakan Cloud Router Switch CSR125-24G-1S-IN disarankan menggunakan Routerbord RB493G dikarenakan mendukung sampai 8 (delapan) virtual MetaRouter.

2. Penelitian ini menerapkan virtual MetaRouter dan konfigurasi dengan user diluar Cloud, disarankan untuk membuat virtual MetaRouter pada Real Scenario dengan penerapan Access Point.

\section{Daftar Pustaka:}

Sutarman, 2012, Pengantar Teknologi Informasi, Bumi Aksara, Jakarta.

S'To, 2016, Mikrotik Metarouter 100\% Illusion, Jasakom, Jakarta.

Haryanto, E., V., 2012, Jaringan Komputer, ANDI, Yogyakarta.

Haerazi, 2015, Perancangan Infrastruktur Jaringan Komputer Kampus (Studi Kasus STAHN Gde Pudja Mataram), Skripsi, Teknik Informatika, STMIK Lombok, Praya.

Hermanto, Dwi; Sudarmawan, 2015, Analisis Dan Implementasi Fitur Metarouter Mikrotik Untuk Loadbalance Dan Qos Menggunakan Mikrotik RB751U-2HND Pada Jaringan Global Media Solusindo, Skripsi, Teknik Informatika, STMIK AMIKOM, Yogyakarta

Lombok, Maulana Ashari-STMIK. "Audit Information Technology (IT) Governance Pada Sekolah Tinggi Manajemen Informatika Dan Komputer (STMIK) Lombok Menggunakan Framework COBIT 4.1." Bianglala Informatika 3.2 (2015).

Lombok, Wire Bagye-STMIK. "Analisis Tingkat Kematangan Sistem Informasi Akademik Menggunakan Framework COBIT 4.1 (Studi Kasus: STMIK Lombok)." Speed-Sentra Penelitian Engineering dan Edukasi 8.1 (2016).

Hodia, Maelani, and Khairul Imtihan-STMIK Lombok. "Perancangan Sistem Informasi Praktek Klinik Kebidanan (PKK) Pada Prodi 
MISI (Jurnal Manajemen Informatika \& Sistem Informasi) - Volume 1 No 1 - 2018 http://e-journal.stmiklombok.ac.id/index.php/misi

DIII Kebidanan Stikes Qamarul Huda." IJNSIndonesian Journal on Networking and Security 6.3 (2017).

Lombok, Hairul Fahmi-STMIK. "Efektifitas Wireless Lan Berbasis 802.11 b/g Sebagai Solusi Jaringan Kampus (Studi Kasus: Sekolah Tinggi Agama Hindu (STAHN) Gde Pudja Mataram." IJNS-Indonesian Journal on Networking and Security 4.4 (2015). 